\title{
Delivering informatics for clinical research in developing countries
}

\author{
Jonathan Babbage ${ }^{1 *}$, Naga S Nagisetty ${ }^{1}$, Steven P Larmore ${ }^{1}$, Jacqueline Fiore ${ }^{2}$ \\ From 11th Annual UT-ORNL-KBRIN Bioinformatics Summit 2012 \\ Louisville, KY, USA. 30 March - 1 April 2012
}

\section{Background}

Not all diseases exist in locations where they are easy to study. The International Centers of Excellence for Malaria Research [1] bring the critical infrastructure necessary for research to parts of these endemic regions. We have implemented some of the existing health care informatics capabilities that deliver on the specific research requirements in a fast, accurate, and secure way in a developing

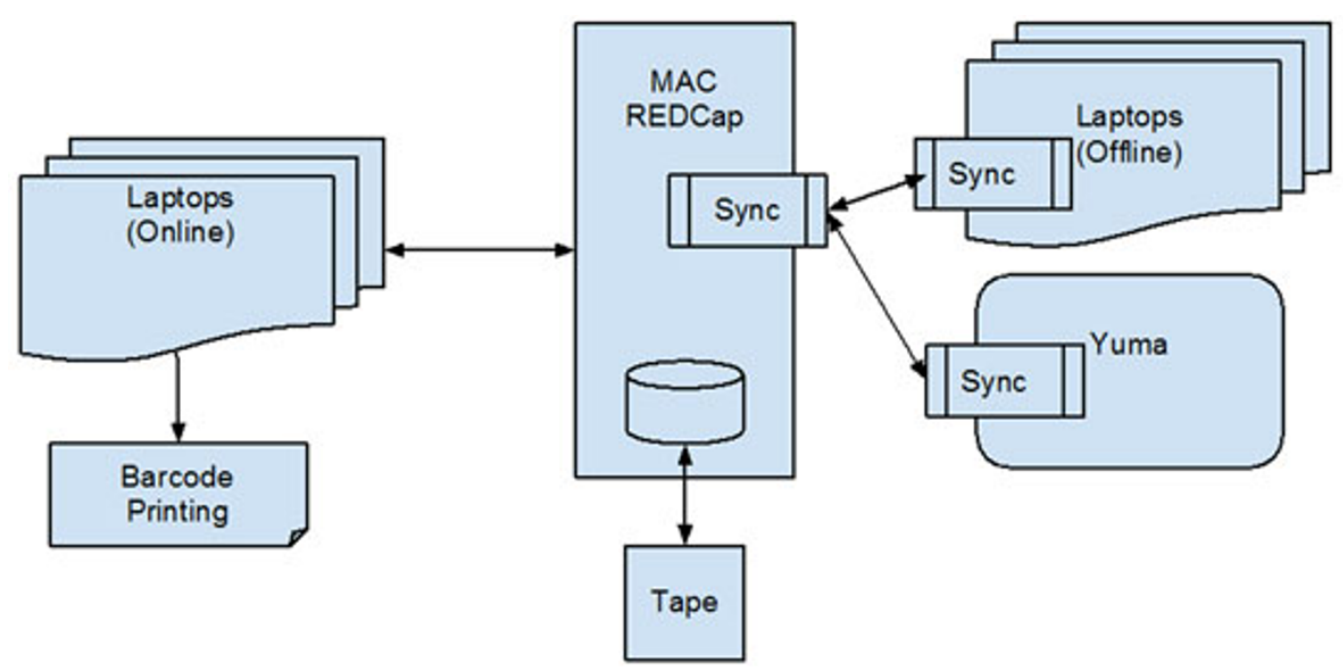

Online Features

Barcode Printing

Subject Creation Utity

Search by barcode or subject

No inline subject creation
Server Features

Server Sync
Offine Features

No barcode printing

No subject creation utility

Search by barcode or subject

No inline subject creation

(Yuma) GPS integration with

REDCap

Encrypted MySQL

Client Sync

Figure 1 Infrastructure diagram.

\footnotetext{
* Correspondence: jonathan.babbage@hc.msu.edu

${ }^{1}$ Clinical and Translational Sciences Institute, Michigan State University, East Lansing, MI 48824, USA

Full list of author information is available at the end of the article
} 
country [2]. Our approach has been modified to work around some of the unique conditions present in these areas. Challenges have included identifying appropriate hardware and software for the studies, delivering the hardware to Malawi (Southern Africa), limited network connectivity, mobility constraints, GPS data collection, barcode generation, local customs, and limited availability of information technology staff.

\section{Materials and methods}

We present an informatics approach that was implemented in Malawi to accommodate six different facilities, over twenty staff members doing data entry, and one field data collector that travels to subjects' houses. The approach we implemented included a server installation at the Malaria Alert Center (MAC) in Blantyre, offline data capture devices (running a customized version of REDCap [3]), sample barcoding, and integrated location capture for the geographical statistics. The server acts as the central repository for both the study metadata and the data from the offline data capture systems. The data collection team will use the offline device to collect the data while at a regional health facility or district hospital. They return to the MAC at the end of the day and migrate the data to the server. The customized version of REDCap acts as the offline EDC and GPS data collection tool which allows for subject identification using a barcode as opposed to hand entered ids. We provided necessary training sessions to the study personnel on configuring the data capture systems for individual studies, managing the infrastructure, and using the different components to capture the data effectively. Two months after launch we are approaching 10,000 subjects enrolled and their corresponding samples. We will discuss successes and setbacks we have experienced.

\footnotetext{
Author details

${ }^{1}$ Clinical and Translational Sciences Institute, Michigan State University, East Lansing, MI 48824, USA. ${ }^{2}$ Malaria Alert Centre, University of Malawi College of Medicine, Blantyre, Malawi.
}

Published: 31 July 2012

\section{References}

1. Rao M: The international centers of excellence for malaria research. Acta Trop 2012, 121(3):157.

2. Nguyen $\mathrm{T}, \mathrm{Vu} \mathrm{H}$, Webster J, Nimunkar A: A Web-based electronic medical records and hospital information system for developing countries. J Health Inform in Developing Countries 2011, 5(1):155-70.

3. Harris P, Taylor R, Thielke R, Payne J, Gonzalez N, Conde J: Research electronic data capture (REDCap) - A metadata-driven methodology and workflow process for providing translational research informatics support. J Biomed Inform 2009, 42(2):377-81.

doi:10.1186/1471-2105-13-S12-A24

Cite this article as: Babbage et al:: Delivering informatics for clinical research in developing countries. BMC Bioinformatics 2012 13(Suppl 12): A24.

\section{Submit your next manuscript to BioMed Central and take full advantage of:}

- Convenient online submission

- Thorough peer review

- No space constraints or color figure charges

- Immediate publication on acceptance

- Inclusion in PubMed, CAS, Scopus and Google Scholar

- Research which is freely available for redistribution 